\title{
Practical Research on Rearing Broodstock Abalone Using a Closed Recirculating System
}

\author{
Yukio MATSUMOTO* and Tomoki MAEDA \\ Miyako Laboratory, Tohoku National Fisheries Research Institute, Japan Fisheries Research and \\ Education Agency, Miyako, Japan
}

\begin{abstract}
Hatcheries in Japan's Tohoku region induce the gonadal maturation of Haliotis discus hannai by controlling the water temperature. However, the cost of heating the water places financial pressure on the hatcheries. This study showed that the heating cost in rearing abalone broodstock can be reduced using a simple closed recirculating system that was constructed using common commercial products. During our experiment, the water quality parameters including ammonia-, nitrite- and nitratenitrogen were kept under recommended safety levels. $\mathrm{pH}$ did not show a significant decrease during the breeding period. Although the calcium ion concentration and salinity value were less stable in the closed recirculating system than in the flow-through system, both were within adequate levels for rearing abalone over long periods. Moreover, the gonadal maturation of $H$. discus hannai was not inhibited by rearing in a closed recirculation system. And the electric power consumption in the closed recirculating system was reduced to about one-seventh of that in the flow-through system.
\end{abstract}

Discipline: Fisheries

Additional key words: biofilter, Haliotis discus hannai, hatcheries

\section{Introduction}

Abalone seeds are widely produced worldwide for their stock enhancement and aquaculture. Hatcheries of the Pacific abalone (Haliotis discus hannai) in the Tohoku region of Japan induce the gonadal maturation of broodstock abalone by temperature control. Although this technique is an efficient method for the maturation of abalone broodstock, the water temperature must be maintained at more than $10^{\circ} \mathrm{C}$ warmer than the ambient water temperature and air temperature during winter. These additional fuel costs place financial pressure on the hatcheries. At present, almost all Japanese hatcheries use a flow-through conditioning unit. Therefore, we tested whether a closed recirculating system, which purifies and reuses warmed seawater, could induce the gonadal maturation of $H$. discus hannai and reduce the heating cost of water. In the present study, we constructed a simple closed recirculating system with common commercial products that could be easily introduced to hatcheries in the future. Moreover, the dynamics of total ammonium nitrogen (TAN: $\mathrm{NH}_{3}-\mathrm{N}+\mathrm{NH}_{4}-\mathrm{N}$ ), ammonia-, nitrite- and nitrate-nitrogen, which are toxic to Haliotis species, were compared between the closed recirculating system and flow-through system. In addition, $\mathrm{pH}$, salinity, and calcium ions, which are toxic to Haliotis species and affect shell formation, were also compared between both systems. After rearing, the electric power consumption of the closed recirculating system was compared with that of the flow-through system, and egg collection was conducted to assess the spawner performance of abalone reared in the closed recirculating system.

\section{Materials and methods}

\section{Experimental system and treatment of broodstock}

Abalone were reared in a $100-\mathrm{L}$ water tank (rearing tank, Appendix 1 and Appendix 2 (c)) with a density of approximately $700 \mathrm{~g}$ of broodstock abalone (Table 1), as about $7 \mathrm{~kg}$ of broodstock abalone are often reared in 1,000-L tanks in Japanese hatcheries (Omori et al. \& Ishida 1995). The broodstock abalone were reared in shelters with raised-bottomed cages (Appendix 1 and Appendix 2 (c)), and were fed approximately 100-140 g/ tank salted and boiled Japanese kelp (Saccharina

*Corresponding author: matsumoto_yukio79@fra.go.jp

Received 4 October 2019; accepted 15 March 2020. 
Table 1. Rearing conditions of each experimental tank

\begin{tabular}{ccccccc}
\hline \hline & Total weight of adult (g) & $\begin{array}{c}\text { Number } \\
\text { of abalones }\end{array}$ & $\begin{array}{c}\text { Mean } \\
\text { weight } \pm \text { SD (g) }\end{array}$ & $\begin{array}{c}\text { Mean shell } \\
\text { length } \pm \text { SD (mm) }\end{array}$ & $\begin{array}{c}\text { Survial rate of } \\
\text { adult (\%) }\end{array}$ \\
\hline \multirow{2}{*}{$\begin{array}{c}\text { Closed } \\
\end{array}$} & Tank1 & 781 & 7 & $112 \pm 79$ & $97 \pm 18$ & 57 \\
Tank2 & Tank3 & 738 & 6 & $122 \pm 31$ & $98 \pm 9$ & 100 \\
system & Tank4 & 710 & 8 & $100 \pm 25$ & $92 \pm 9$ & 100 \\
& Tank5 & 760 & 7 & $102 \pm 45$ & $92 \pm 13$ & 57 \\
Flow & Tank6 & 742 & 11 & $69 \pm 17$ & $83 \pm 8$ & 73 \\
through & Tank7 & 720 & 7 & $106 \pm 21$ & $94 \pm 8$ & 100 \\
system & Tank8 & 696 & 6 & $103 \pm 18$ & $93 \pm 5$ & 83 \\
\hline
\end{tabular}

japonica) every 2-3 days, with the uneaten feed being checked. The water temperature in the tank was maintained using a heater at approximately $18^{\circ} \mathrm{C}-20^{\circ} \mathrm{C}$ to effectively induce maturation (Uki \& Kikuchi 1984).

Closed recirculating system: Appendixes 1 and 2 show an overview of the closed recirculating system used in the present study. The closed recirculating system consists of a rearing tank, biofilter, and settlement tank, and has an effective water volume of $150 \mathrm{~L}$. In this system, a nitrifier in the biofilter removes the ammoniaand nitrite-nitrogen, which are toxic against Haliotis species; however, there is no available equipment for the removal of nitrate-nitrogen. The breeding water from the rearing tank originates from the settlement tank in which solid particles such as feces and uneaten feed are removed by gravitational separation. After the removal of these solid particles, the breeding water passes through the biofilter to remove the toxic ammonia and then returns to the rearing tank at a rate of $144 \mathrm{~L} / \mathrm{h}$. In the biofilter, $30 \mathrm{~L}$ of crushed oyster shells (particle size: $4 \mathrm{~mm}-7 \mathrm{~mm}$; Maruei Co., Ltd., Japan) are used as the biofilter medium. The shells are placed in net bags (3-mm mesh size), which are then placed in a double-bottom 100-L plastic container (i.e., biofilter, Appendix 2 (a)). Treated sewage in the biofilter is then lifted using aeration $(864 \mathrm{~L} / \mathrm{h})$, which is increased with the number of passes through the filter to facilitate nitrification activity. Prior to the experiment, nitrifying bacteria accumulate in the biofilter. After sterilization of the filter medium with 60-ppm sodium hypochlorite and following neutralization with sodium thiosulfate, fresh seawater and $1 \mathrm{~g}$ of ammonium chloride are added to the tanks at the same time. At the start of nitrifying bacteria incubation, we added about $1.7 \mathrm{~L}$ of sand coral attached with nitrifying bacteria as inoculum. The water temperature is maintained using a heater at approximately $20^{\circ} \mathrm{C}$ to incubate the nitrifying bacteria. Two weeks later, the concentrations of ammonia-, nitrite-, and nitrate- nitrogen were measured. The loss of ammonia-nitrogen and the increase of nitrate-nitrogen indicates "maturation" of the biofilter medium. After confirming the growth of the nitrifier, we replaced the seawater to begin the experiment. Our experiment on nitrification showed that the inoculum could remove 21.4 $\mathrm{mg}$ of ammonia nitrogen per hour at $20^{\circ} \mathrm{C}$ (Maeda, unpublished data). As the density of $700 \mathrm{~g}$ of $\mathrm{H}$. discu hannai (with a shell length of $9 \mathrm{~cm}$ ) could excrete $15.4 \mathrm{mg}$ of TAN/day based on the formula from Park et al. (2009), our biofilter had sufficient nitrification activity to remove ammonia nitrogen from the abalone.

The salinity in the closed recirculating system (see below) increases due to evaporation and salt in the feed. Therefore, we reduced the salinity once a week by using the following method. We added the same amount of fresh water as the evaporated water, and then cleaned out the feces and uneaten feed that accumulated at the bottom of the rearing tank. Cleaning results in the loss of $20 \mathrm{~L}$ of breeding water (13\% of the amount of breeding water). After the cleaning, fresh water and seawater were added to maintain an adequate level of salinity and water volume.

Flow-through system: For a comparison with the closed recirculating system, a flow-through system was constructed using the same flow path as that of the closed recirculating system without the filter medium. The flow-through system supplies $72 \mathrm{~L}$ of sand-filtered seawater per hour. Two heating units are used in this system because the seawater temperature in winter is too low to be heated to $18^{\circ} \mathrm{C}-20^{\circ} \mathrm{C}$.

\section{Water quality and electric power costs}

The time-series data of water quality in the closed recirculating system $(n=6)$ were compared with that of the flow-through system $(\mathrm{n}=2)$. Ammonia-nitrogen includes both ammonium ions $\left(\mathrm{NH}_{4}^{+}\right)$and unionized 
Table 2. Information of abalones before spawning experiment

\begin{tabular}{cccccc}
\hline \hline & & Number of males & Number of females & EAT $\left({ }^{\circ} \mathrm{C} \cdot\right.$ day $)$ & Total weight of females $(\mathrm{g})$ \\
\hline \multirow{2}{*}{$\begin{array}{c}\text { Closed } \\
\text { recirculating } \\
\text { system }\end{array}$} & Tank1 & 1 & 3 & 958 & 358 \\
& Tank2 & 2 & 4 & 992 & 506 \\
& Tank3 & 5 & 3 & 983 & 291 \\
\multirow{2}{*}{$\begin{array}{c}\text { Flow } \\
\text { through }\end{array}$} & Tank5 & 1 & 3 & 946 & 405 \\
system & Tank6 & 5 & 2 & 1,003 & 191 \\
\hline
\end{tabular}

EAT: Effective accumulated temperature. $Y n=\sum_{i=1}^{n}(t i-7.6), \quad Y=$ EAT in degree day, $t i=$ water temperature, $n=$ day.

ammonia $\left(\mathrm{NH}_{3}\right) \cdot \mathrm{NH}_{3}$ is a more toxic form of ammonia than $\mathrm{NH}_{4}^{+}$; however, there is no direct way to measure the concentration of $\mathrm{NH}_{3}$. In the present study, we measured the concentration of $\mathrm{NH}_{4}-\mathrm{N}$ and calculated the concentration of $\mathrm{NH}_{3}-\mathrm{N}$ based on the methodology described by Bower and Bidwell (1978). $\mathrm{NH}_{4}-\mathrm{N}, \mathrm{NO}_{2}-\mathrm{N}$, and $\mathrm{NO}_{3}-\mathrm{N}$ were measured using a Hach DR6000 spectrophotometer (Hach Company) with exclusive reagents $\left(\mathrm{NH}_{4}-\mathrm{N}\right.$, : Hach 1336 and Hach 1337; $\mathrm{NO}_{2}-\mathrm{N}$ : Hach 0596; $\mathrm{NO}_{3}-\mathrm{N}$ : Hach 0586, Hach Company) once a week. Calcium ions and salinity were measured once a week using a B-751 compact calcium ion meter (Horiba, Ltd.) and a New S-100 $\alpha$ salinity meter (Tanaka Sanjiro Co., Ltd.), respectively. As the calcium ion meter has measurement error $( \pm 10 \%)$, calcium ions in the closed recirculating system were evaluated as a relative value between the closed recirculating system and the flowthrough system (i.e., difference of calcium ions in the closed recirculating system from the average values of calcium ions in the flow-through system). Water temperature and $\mathrm{pH}$ were measured daily with a KP-10Z meter (Kasahara Chemical Instruments Corp.) from Monday to Friday. An EC-03N wattmeter (Custom corporation Co., Ltd.) was used to measure electric power consumed by the PMD-0532B2B2 water pump (Sanso Electric Co., Ltd.) and TH1-1 heating system (Tanaka Sanjiro Co., Ltd.) employed in our systems for a comparison of electric power consumption between both systems.

\section{Comparison of abalone spawner performance}

Table 2 presents details of the experimental abalone. The broodstock abalone reared in each 100-L tank were moved to the $15-\mathrm{L}$ tanks to induce spawning, with the abalone being segregated by rearing tanks and by gender. According to Uki and Kikuchi (1984), the four levels of gonad index (0 to third grade) of the experimental abalone were checked before the spawning experiment. Spawning was induced by exposing the abalone to seawater treated with high levels of ultraviolet light $\left(800 \mathrm{MWh} \mathrm{L}^{-1}\right)$. The eggs were fertilized by the sperm of males reared in the same 100-L tanks. All eggs released within $2 \mathrm{~h}$ after release of the first eggs were fertilized. The fertilization rate and number of fertilized eggs were recorded by checking the cleavage $2 \mathrm{~h}$ after fertilization. To estimate the number of eggs, we counted $5 \mathrm{~mL}$ of suspension containing fertilized eggs and calculated the total number of eggs. The normality rate of larvae that can attach to the substrate was counted 5 days after fertilization. In our experiment, abnormity was defined as the larvae that were unable to withdraw their foot in Lugol's eosin solution (a mixture of $0.85 \%$ sodium chloride solution and $1 \%$ eosin solution). The effects of the rearing system on electric power consumption, the number of eggs released per 100-g body weight, the fertilization rate, and the normality rate of larvae were tested using a generalized linear model (GLM) with a link function corresponding to the probability distribution of the response variables. The effect of explanatory variables was tested with likelihood ratio tests using the "Anova" function in the car package $\mathrm{R}$ v3.5.2. The gonad index of males and females were compared between the closed recirculating system and the flow-through system using the Mann-Whitney $U$ test (exactRankTests $R$ package v3.5.5) because the gonad index is ordered categorical data.

\section{Results and discussion}

\section{Comparison of water quality and electricity costs}

For Haliotis species, the concentration of TAN and $\mathrm{NH}_{3}-\mathrm{N}$ should be below approximately 1.00 (Leighton 2008) - $1.12 \mathrm{mg} / \mathrm{TAN}$ (Cheng et al. 2004a) and 0.016 (Reddy-Lopata, Auerswald, \& Cook 2006) - 0.025 mg/L $\mathrm{NH}_{3}-\mathrm{N}$ (Leighton 2008), respectively. Our closed recirculating system kept the concentration of TAN 

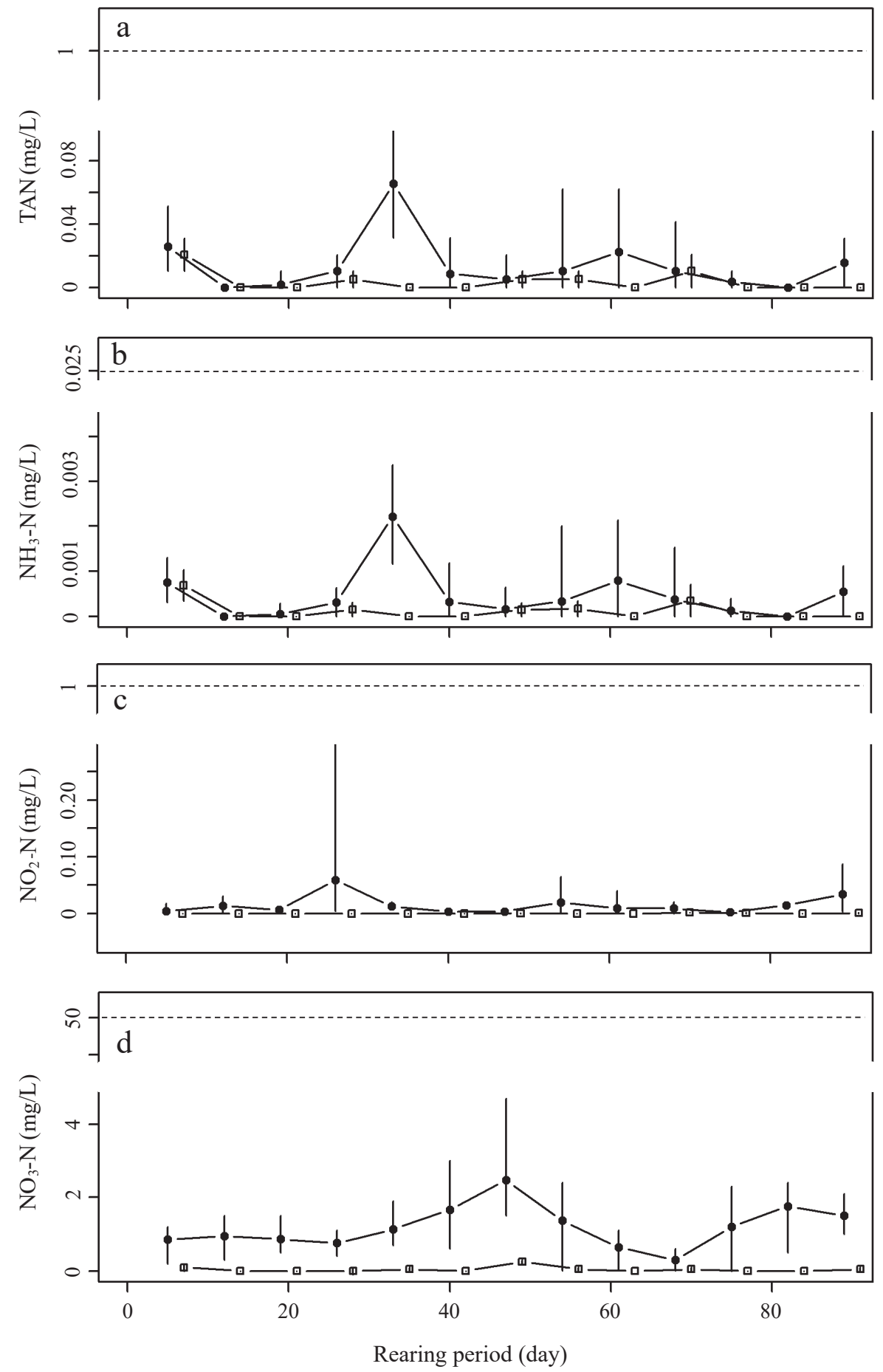

Fig. 1. Time-series changes of (a) total ammonium nitrogen TAN, (b) NH4-N, (c) $\mathrm{NO}_{2}-\mathrm{N}$, and (d) $\mathrm{NO}_{3}-\mathrm{N}$ during the experiment ( $\bullet$ : closed recirculating system; $\square$ : flow-through system)

Error bar indicates max-min range of data. The horizonal dashed lines indicate the non-toxic level suggested by Leighton (2008).

(Fig. 1 (a)) and $\mathrm{NH}_{3}-\mathrm{N}$ (Fig. 1 (b)) below toxic levels. Figure 1 (c) indicates that the concentration of $\mathrm{NO}_{2}-\mathrm{N}$ was below the toxic level affecting growth $(0.56 \mathrm{mg} / \mathrm{L}$ $\mathrm{NO}_{2}-\mathrm{N}$, Harris et al. 1997) and immune response (0.96 $\mathrm{mg} / \mathrm{L} \mathrm{NO}-\mathrm{N}$, Cheng et al. 2004b). Moreover, Leighton
(2008) suggested that the concentration of $\mathrm{NO}_{2}-\mathrm{N}$ should be below $0.5 \mathrm{mg} / \mathrm{L}$ for Haliotis species. We replaced $20 \mathrm{~L}$ of breeding water per week, which could decrease TAN, $\mathrm{NH}_{3}-\mathrm{N}$, and $\mathrm{NO}_{2}-\mathrm{N}$. However, as our simple simulation indicated that $20 \mathrm{~L}$ of water replacement per week is not 
enough to keep TAN below the toxic level (Appendix 3), nitrification of the biofilter removed most of the $\mathrm{NH}_{4}{ }^{+}$and $\mathrm{NH}_{3}$. Actually, $\mathrm{NO}_{3}-\mathrm{N}$ was higher than that of the flowthrough system (Fig. 1 (d)). Our system included no equipment to remove $\mathrm{NO}_{3}{ }^{-}$, though the concentration of $\mathrm{NO}_{3}-\mathrm{N}$ was below the toxic level $\left(50-250 \mathrm{mg} / \mathrm{L} \mathrm{NO}_{3}-\mathrm{N}\right)$ for Haliotis species (Basuyaux \& Mathieu 1999; Leighton 2008, Fig. 1 (d)). The replacement of breeding water (20 $\mathrm{L} /$ week) could cause the low concentration of $\mathrm{NO}_{3}-\mathrm{N}$ in this study. Our results indicated that $30 \mathrm{~L}$ of biofilter medium ( $30 \%$ of rearing tank volume) with the partial replacement of seawater is enough for the removal of $\mathrm{NH}_{4}^{+}, \mathrm{NH}_{3}$, and $\mathrm{NO}_{2}^{-}$from $700 \mathrm{~g}$ of broodstock. In addition, denitrification equipment for removing $\mathrm{NO}_{3}{ }^{-}$is not necessary for abalone broodstock rearing under these conditions. When we introduced a similar recirculating system to a hatchery of $\mathrm{H}$. discus hannai, similar changes in TAN, $\mathrm{NH}_{3}, \mathrm{NO}_{2}-\mathrm{N}$, and $\mathrm{NO}_{3}-\mathrm{N}$ were observed (Appendix 4).

During the experiment, a marked decrease in $\mathrm{pH}$ was not observed (Fig. 2 (a)). A reduction of pH could occur due to the $\mathrm{NO}_{3}{ }^{-}$that accumulates as a consequence of robust nitrification (Hirayama, 1970). The partial replacement of rearing water would probably prevent the accumulation of $\mathrm{NO}_{3}^{-}$and maintain an adequate $\mathrm{pH}$ level. A decrease in calcium ions was observed in abalone aquaculture using the closed recirculating system, as abalone obtain calcium directly from the surrounding seawater similar to other gastropod species (Thomas \& Lough 2006). In our experiment, the calcium ions in the closed recirculating system were below those of the flowthrough system (Fig. 2 (c)). Calcium hydroxide is typically used when calcium ions decrease in land-based closed recirculating systems (Koizumi \&Tsuji 2017). However, replacing the breeding water with fresh seawater or adding small amounts of fresh seawater (e.g., approximately $10 \%$ of the amount of breeding water per day) is convenient for Japanese abalone hatcheries, as fresh seawater is easily obtained. Although salinity in the closed recirculating system was less stable than that in the flow-through system, a suitable range (salinity of 3138 psu; Leighton 2008) was maintained (Fig. 2 (b)), except in a particular tank. We observed high salinity of 39-40 psu on days 47, 54, and 89 in tank 6 (Fig. 2 (b)), where the survival rate of broodstock was $100 \%$ (Table 1). Although short-term high salinity stress may not affect the survival of broodstock, it would be better to replace the breeding water when there are extreme salinity changes in abalone hatcheries. In addition to evaporation, salted and boiled Japanese kelp could also cause increased salinity. Therefore, stable salinity may be maintained by feeding artificial food instead of replacing the breeding water.

One future study concerns an experiment on highdensity rearing based on the ammonia excretion of abalone and biofilter nitrification capability. Our biofilter was apparently over-engineered for $700 \mathrm{~g}$ of broodstock abalone. By increasing the rearing density to reduce the rearing tank, we could reduce the rearing cost, including the heating cost and initial cost of the closed recirculating system. In this study, we replaced some breeding water with fresh water or seawater to remove the leftover feed and feces, and maintained an adequate level of salinity. If the partial replacement of breeding water is needed to maintain water quality, a rearing tank without a biofilter may be useful. Supplying a very small amount of seawater into the tank with insulating material could thus be a reasonable alternative to the closed recirculating system.

Electric power consumption during breeding was compared between both systems. The average electricity cost in the closed recirculating system was about oneseventh of that in the flow-through system (GLM with Gamma distribution and likelihood ratio test, $\chi^{2}=7.14$, $P=1.515 \mathrm{e}-08$, Fig. 3 (a)). In addition, the water temperature in the flow-through system was unstable with rapid decreases sometimes being observed, whereas the closed recirculating system maintained the water temperature at about $20^{\circ} \mathrm{C}$ (Fig. 2 (d)). Cold water from the sight frontage of our facility entering the system (Appendix. 6 (a)), a drop in air temperature (Appendix. 6 (b)), or the simultaneous effects of air and sea temperature could cause a drop in water temperature in the flow-through system. Therefore, the closed recirculating system not only reduced the heating cost but also maintained a suitable water temperature for the gonadal maturation of H. discus hannai.

\section{Comparison of abalone spawner performance}

As the effective accumulated temperature (EAT) reached $900^{\circ} \mathrm{C}$ in all experimental tanks (Table 2), the abalone in our experiment could release their eggs and sperm (Kikuchi \& Uki 1974). The abalone in the closed recirculating system showed greater gonad development than that of abalone in the flow-through system (female gonad index, Mann-Whitney $\mathrm{U}$ test, $w=66.5, P=0.03$, Fig. 3 (b); male gonad index, $w=90, P=0.02$, Fig. 3 (c)). The abalone in a particular tank (tank 8 ) had smaller gonads than those in other tanks (Table 2) as some abalone spawned in 63 days. Unplanned spawning occurred after sudden temperature changes in the flowthrough system (arrow in Fig. 2 (d)). As changes in water temperature may trigger the spawning of Haliotis discus hannai (Ino 1953), unstable water temperatures in the flow-through system may have caused unplanned 

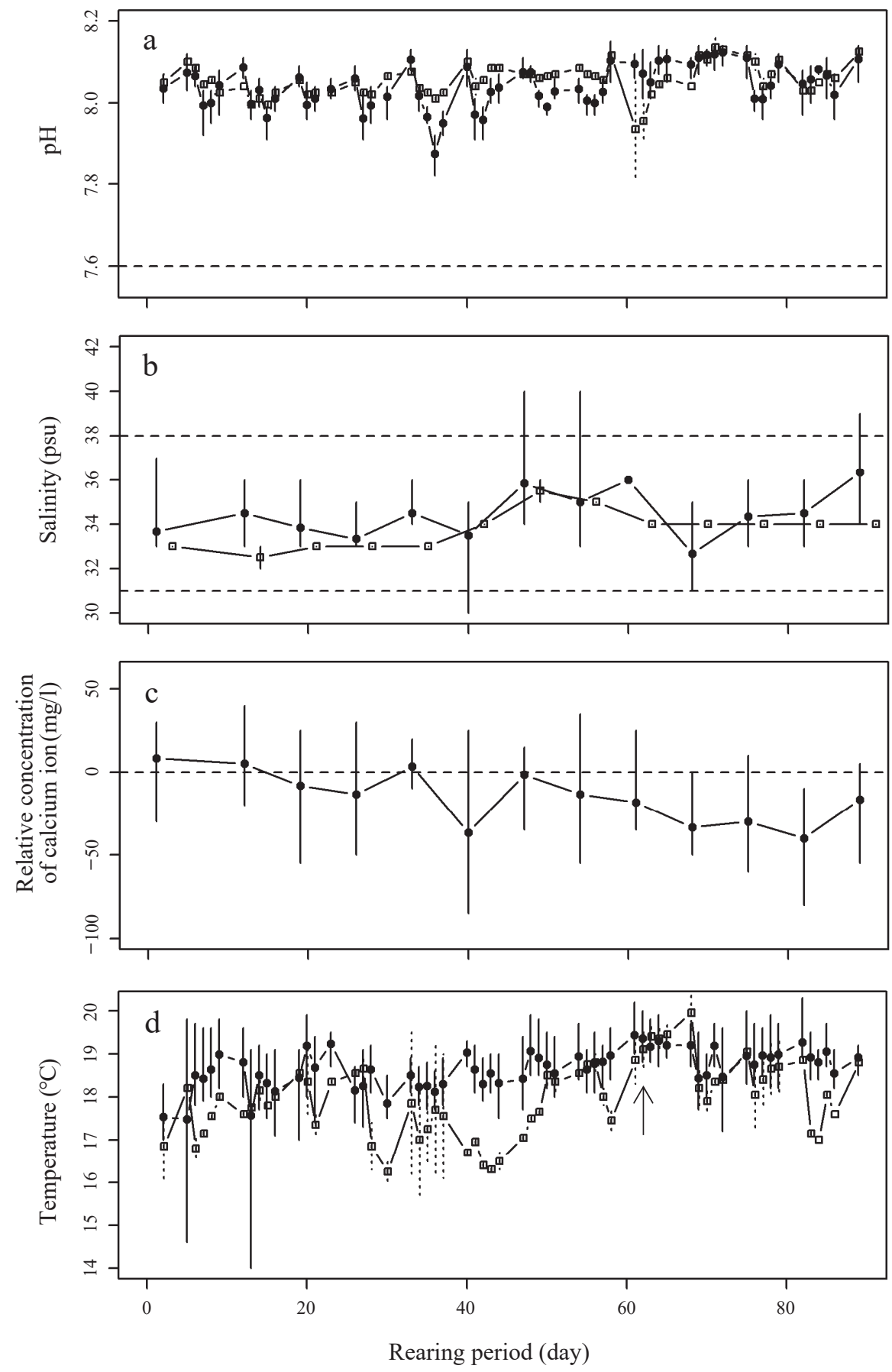

Fig. 2. Time-series changes of (a) salinity, (b) pH, (c) calcium ions, and (d) water temperature during the experiment ( $\bullet$ : closed recirculating system; $\square$ : flow-through system)

Error bar indicates max-min range of data. The horizonal dashed line in (a) indicates the $\mathrm{pH}$ level at which shell elution may occur in Haliotis species (Leighton 2008). The horizonal dashed line in (b) indicates the recommended salinity level (Leighton 2008). The horizonal dashed line in (c) indicates the calcium ion levels in the flowthrough system. 

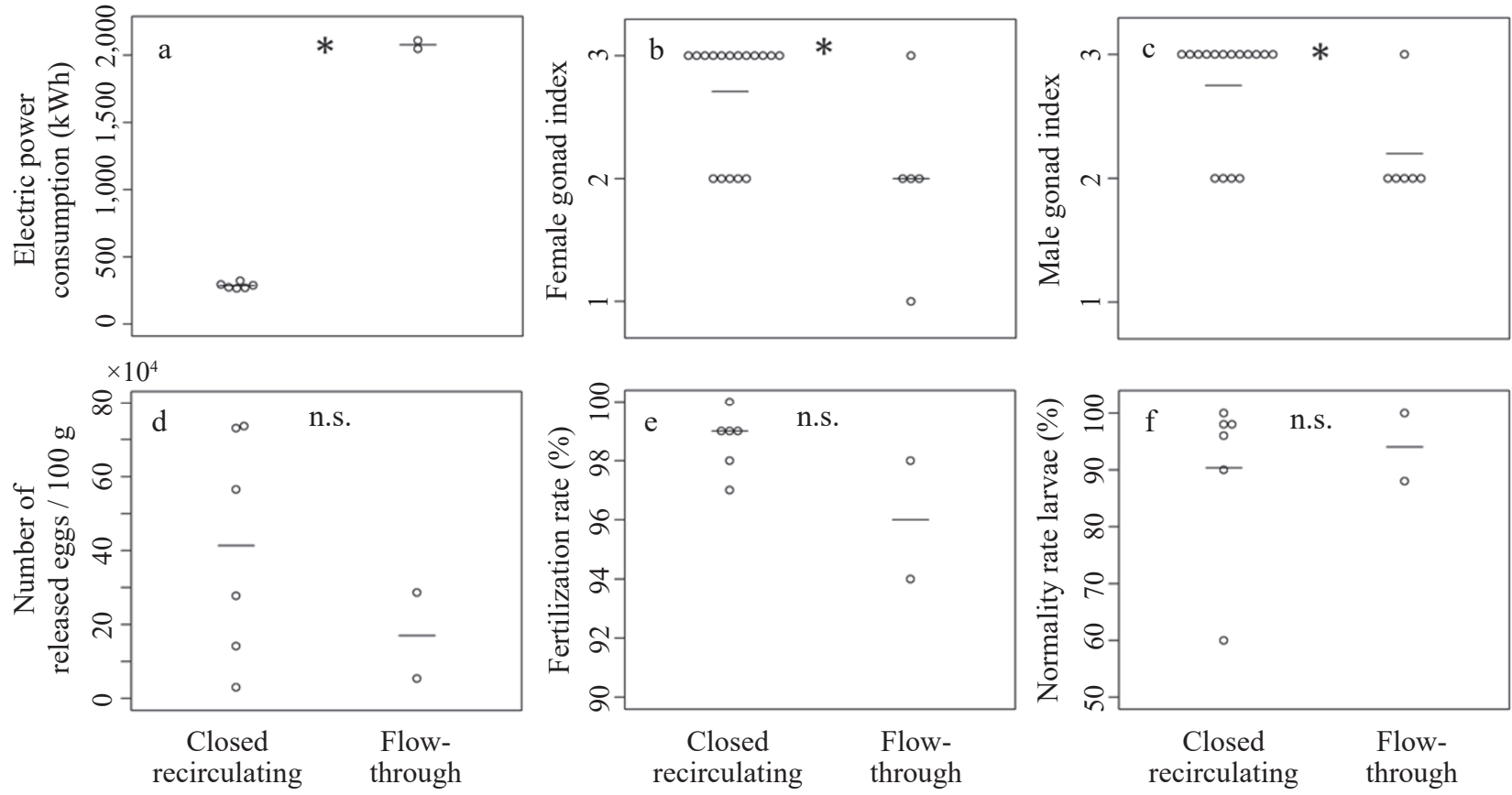

Fig. 3. Comparison of (a) electric power consumption, (b) female gonad index, (c) male gonad index, (d) number of released eggs/100 $\mathrm{g}$ of abalone, (e) fertilization rate, and (f) normality rate of larvae between the closed recirculating system and flow-through system

The solid lines indicate the average values.

*denotes significant differences between the groups; n.s. indicates not significant.

Gonad index: 0 - Immature; 1- sex can be determined from gonad color; 2 - abalone with gonad not bulging at shell edge; 3 - abalone with large gonad bulging at shell edge.

spawning. The number of eggs released per 100-g body weight in the closed recirculating system was also greater than or equal to that of the flow-through system (GLM with negative binomial distribution and likelihood ratio test, $\chi^{2}=1.38, P=0.24$, Fig. 3 (d)). There was no difference in fertilization rate between both systems (GLM with binomial distribution and likelihood ratio test, $\chi^{2}=0.05, P$ $=0.83$, Fig. 3 (e)). As the fertilization rate is generally about $90 \%$ in the hatcheries of $H$. discus hannai (Omori, Kawahara, \& Ishida 1995), we felt that eggs and sperm in the closed recirculating system could be useful in the hatcheries. The normality rate of larvae from the closed recirculating system was similar to that from the flowthrough system (GLM with binomial and likelihood ratio test, $\chi^{2}=0.02, P=0.88$, Fig. 3 (f)). The normality rate of larvae in the closed recirculating system exceeded $90 \%$ (Fig. 3 (f)), which was comparable to the performance at hatcheries in the Tohoku region (Kawahara \& Yamaguchi 1988). However, larvae from a certain closed recirculating system tank (tank 4, Table 2) showed a low normality rate. The larvae with a low normality rate were housed at higher densities than in other tanks until hatching. Given the risk of oxygen depletion at high-density (Leighton 2008), the low normality rate of larvae may be explained by the number of eggs housed before hatching, rather than a difference in rearing methods. Our results showed that abalone spawner performance in the closed circulating system could be the same as in the flowthrough system. In the future, such performance in the closed recirculating system should be tested on a mass scale of seed production.

\section{Conclusion}

The present study showed that abalone broodstock could be reared using a closed recirculating system within the range of the number of abalone in the study. Our results of the closed recirculating system with partial water replacement indicated the possibility that highdensity abalone could be reared using the same system. The biofilter used in this study had adequate nitrification capability, although partial water replacement was needed to maintain suitable salinity and remove leftover feed and feces. Our system could be introduced to existing hatcheries in order to reduce the heating cost in cold regions. In southern species of Haliotis species, egg production is inhibited by high water temperatures caused by global warming (Kiyomoto et al. 2012); therefore, it may be necessary to cool the seawater to induce abalone maturation in the future. Our system 
could also become useful in regions affected by global warming and not only in cold regions.

\section{Acknowledgments}

We wish to thank Mr. Masahiko Hatakeyama and Mr. Koushin Nakamura of the Taro-cho Fisheries Cooperative Association for assisting in our preliminary experiment. We would also like to thank Ms. Fukumi Tashiro of the Tohoku National Fisheries Research Institute for assisting in our experiment. This study was supported by the Sanriku Fund.

\section{References}

Basuyaux, O. \& Mathieu, M. (1999) Inorganic nitrogen and its effect on growth of the abalone Haliotis tuberculata Linnaeus and the sea urchin Paracentrotus lividus Lamarck. Aquaculture, 174, 95-107.

Bower, C. \& Bidwell, J. (1978) Ionization of ammonia in seawater: effects of temperature, $\mathrm{pH}$, and salinity. J. Fish. Res. Board Can., 35, 1012-1016.

Cheng, W. et al. (2004a) Effect of ammonia on the immune response of Taiwan abalone Haliotis diversicolor supertexta and its susceptibility to Vibrio parahaemolyticus. Fish Shellfish Immunol., 17, 193-202.

Cheng, W. et al. (2004b) Effect of nitrite on immune response of Taiwan abalone Haliotis diversicolor supertexta and its susceptibility to Vibrio parahaemolyticus. Dis. Aquat. Organ., 60, 157-164.

Harris, J. O. et al. (1997) Effect of nitrite on growth and oxygen consumption for juvenile greenlip abalone. Haliotis laevigata Donovan. J. Shellfish. Res., 16, 395-401.

Hirayama, K. (1970) Studies on water control by filtration through sand bed in a marine aquarium with closed circulating system-VI. Bull. Jap. Soc. Sci. Fish., 36, 26-34.

Ino, T. (1953) Biological studies on the propagation of Japanese abalone (genus Haliotis). Bull. Tokai. Reg. Fish. Res. Lab.,
5, 1-102 [In Japanese].

Kawahara, I. \& Yamaguchi, H. (1988) Ezo awabi yousei kanri gijyutsu no kairyou ni tsuite (Improvement of rearing method of abalone larvae). Iwate nanbu saibai gyogyou sentar jigyou houkoku syo (Annual report of the Iwate Stock Enhancement Center), 1, 20-27 [In Japanese].

Kikuchi, S. \& Uki, N. (1974) Technical study on artifical spawning of abalone, genus Haliottis I. relation between water temperature and advansing sexual maturity of Haliotis discus hannai ino. Bull. Tohoku Reg. Fish. Res. Lab., 33, 69-78 [In Japanese with English summary].

Kiyomoto, S. et al. (2012) Influences of water temperature and food conditions on growth and maturation of reared warm water abalones. Nippon Suisan GAKKAISHI (J. Jpn. Soc. Fish. Sci.), 78, 1198-1201 [In Japanese].

Koizumi, Y. \& Tsuji, Y. (2017) Abalone Haliotis spp. In Application of Recirculating Aquaculture Systems in Japan, ed. Takeuchi, T., Springer, Berlin, Germany, pp. $175-211$

Leighton, P. (2008) Abalone Hatchery Manual. Aquac. Explain., 25, 1-89.

Omori, M. et al. (1995) Ezo awabi syubyou seisan gijyutsu no jissai: Awabirui no syubyou seisan gijyutsu (Practice of seed produsing of Haliotis discus hannai: Seed producing technique of abalone species), eds. Uki, N. et al., Nihon saibai gyogyou kyoukai, Tokyo, Japan [In Japanese].

Park, J. et al. (2009) Feces production and ammonia excretion of Pacific abalone, Haliotis discus hannai, fed kelp, Laminaria japonica, in relation to water temperature and shell length. J. World Aquac. Soc., 40, 207-215.

Reddy-Lopata, K. et al. (2006) Ammonia toxicity and its effect on the growth of the South African abalone Haliotis midae Linnaeus. Aquaculture, 261, 678-687.

Thomas, J. D. \& Lough, A. (2006) The effects of external calcium concentration on the rate of uptake of this ion by Biomphalaria glabrata (Say). J. Anim. Ecol., 43, 861-871.

Uki, N. \& Kikuchi, S. (1984) Regulation of maturation and spawning of an abalone, Haliotis (Gastropoda) by external environmental factors. Aquaculture, 39, 247-261. 


\section{Appendix 1}

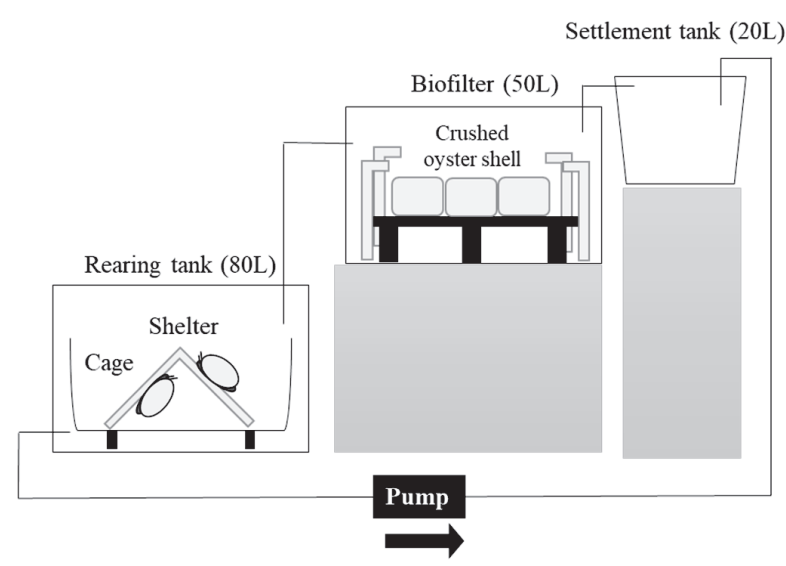

Schematic overview of the closed recirculation system. Numbers enclosed in brackets denote the effective water volume of each tank.

\section{Appendix 2}

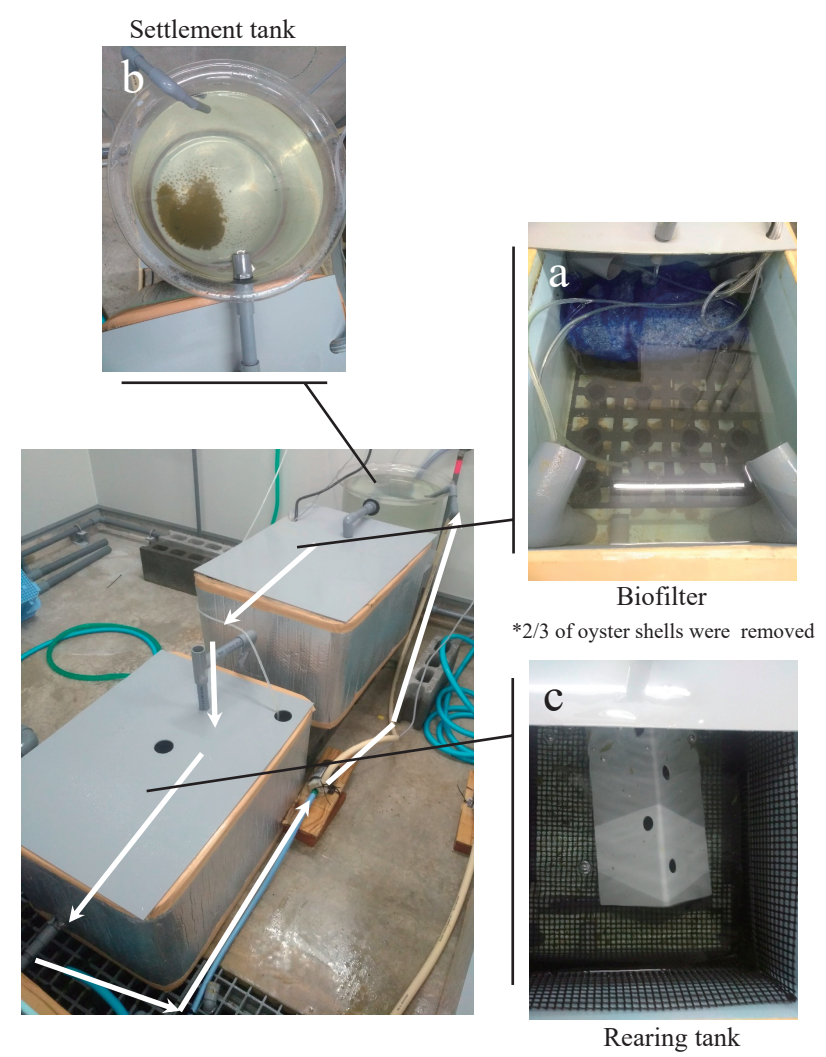

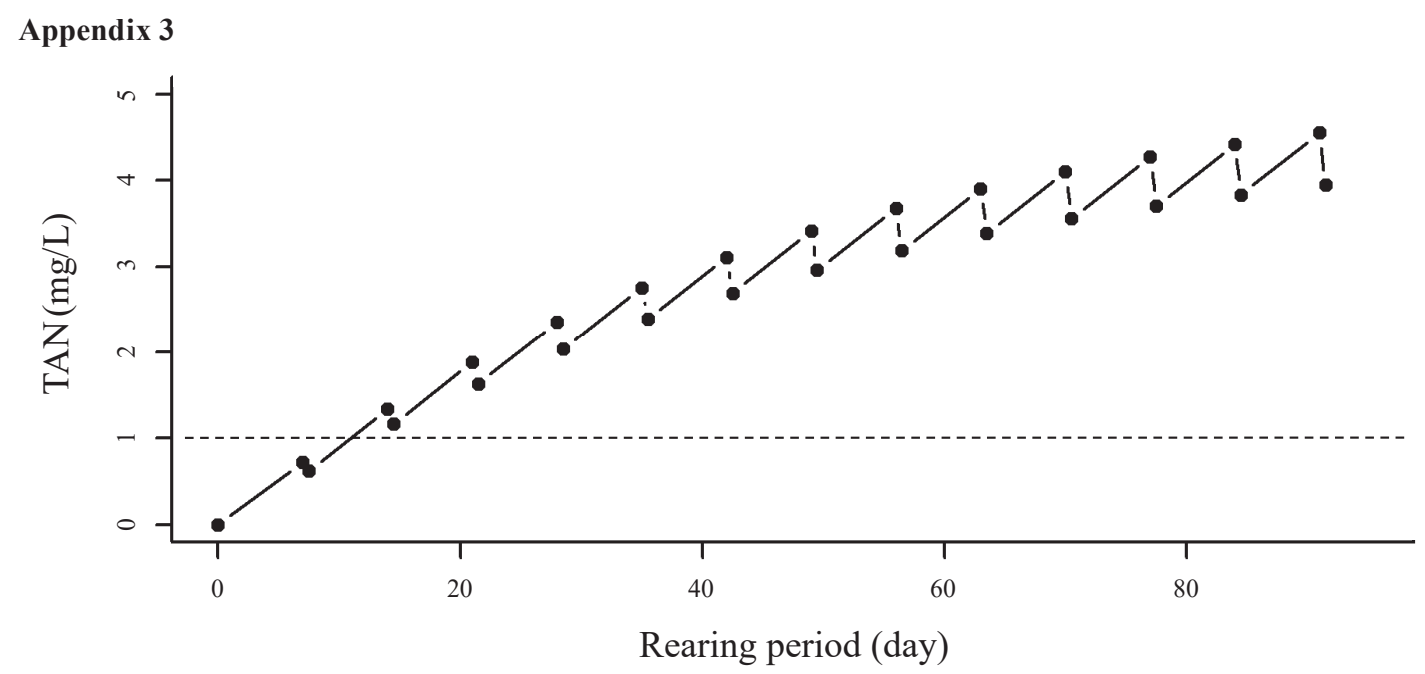

Simulation for time-series changes of total ammonium nitrogen (TAN) in the tank without a biofilter. Breeding water was replaced with $20 \mathrm{~L}$ of seawater per week in this simulation. The excretion rate of TAN from $700 \mathrm{~g}$ of broodstock abalone was calculated based on Park et al. (2009). The horizonal dash lines indicate the non-toxic level suggested by Leighton (2008). 
Appendix 4
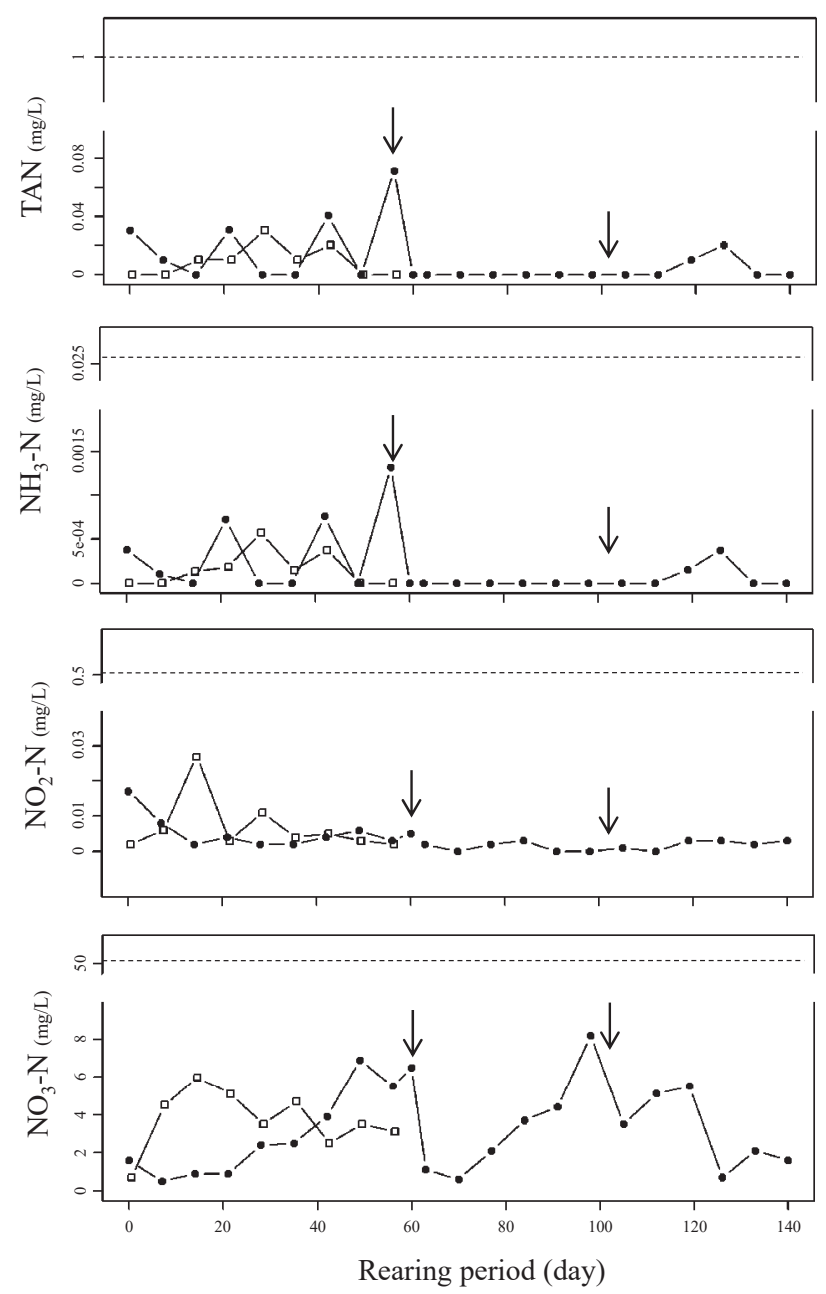

Time-series changes of (a) total ammonium nitrogen, (b) NH4-N, (c) NO2-N, and (d) NO3-N when rearing $7 \mathrm{~kg}$ of broodstock abalone using $150 \mathrm{~kg}$ of coral sand as the biofilter medium in Japanese hatcheries (•: 2017/12/21-2018/5/15; $\square: 2018 / 3 / 15-2018 / 5 / 10)$. The closed recirculating system consists of a rearing tank (1,000-L FRP tank) and a biofilter (1,000-L FRP tank), and has an effective water volume of 1,500 L. The breeding water was replaced with seawater on February 19 and April 4, $2018(\downarrow)$. The horizonal dash lines indicate the non-toxic level suggested by Leighton (2008).

\section{Appendix 5}
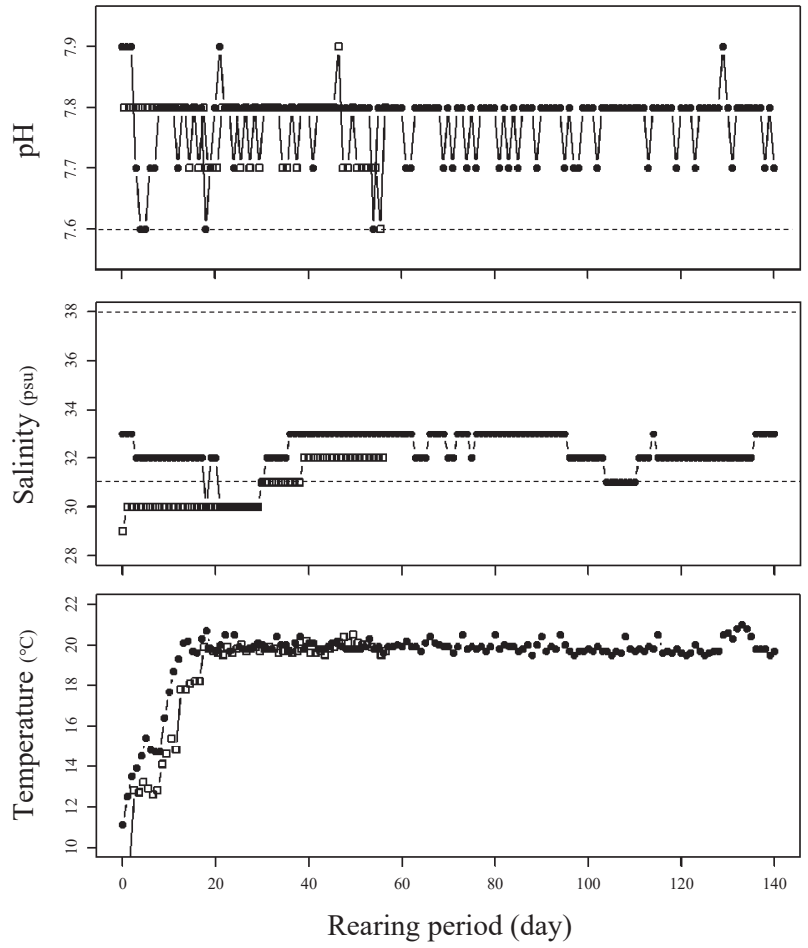

Time-series changes of (a) $\mathrm{pH}$, (b) salinity, and (c) temperature during rearing in the hatcheries (•: 2017/12/21-2018/5/15; 口: 2018/3/15-2018/5/10).

\section{Appendix 6}
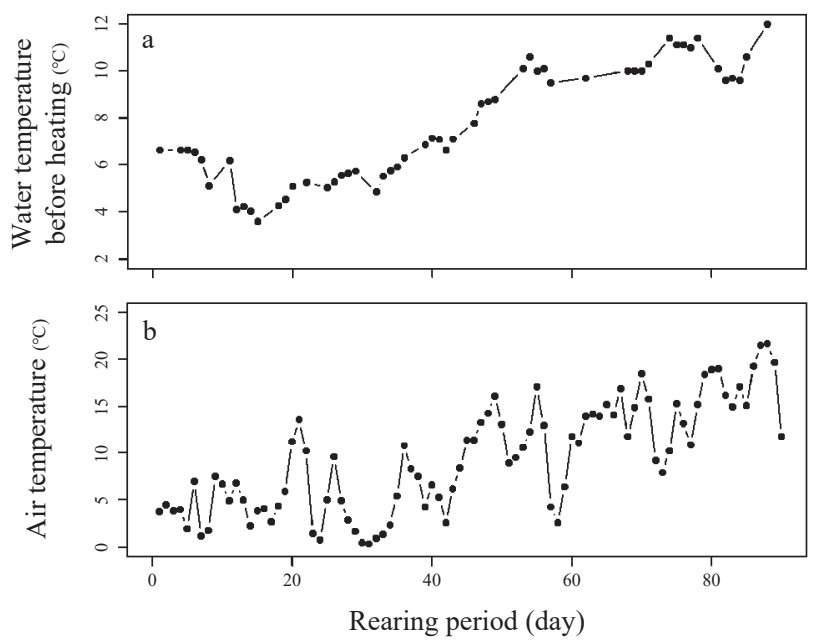

Time-series changes of (a) water temperature before heating and (b) air temperature during the experiment. Water temperature was recorded once a day except on weekends. Mean air temperature information was acquired from dataset provided by the Japan Meteorological Agency (https://www. jma.go.jp/jma/menu/menureport.html). 